\title{
PROBLEM-BASED LEARNING (PBL) E INTERDISCIPLINARIDADE NO ENSINO- APRENDIZAGEM DE ENGENHARIA DE SOFTWARE
}

\author{
PROBLEM-BASED LEARNING (PBL) Y INTERDISCIPLINARÍA EN LA ENSEÑANSA \\ Y APRENDIZAGE DE INGENIERÍA DE SOFTWARE
}

\section{PROBLEM-BASED LEARNING (PBL) AND INTERDISCIPLINARITY IN SOFTWARE ENGINEERING TEACHING-LEARNING}

\author{
Paulo Roberto CÓRDOVA ${ }^{1}$ \\ Joel Haroldo BAADE ${ }^{2}$ \\ Adelcio Machado dos SANTOS ${ }^{3}$
}

RESUMO: A educação superior é determinante na construção de uma sociedade em suas diferentes dimensões. A capacidade de resolver problemas requer competências interdisciplinares. O objetivo desta pesquisa-ação foi avaliar a efetividade da problem-based learning (PBL) para o ensino interdisciplinar em engenharia de software (ESW). Foram conduzidas tutorias com alunos de um curso de Sistemas de Informação. Um questionário foi aplicado àqueles que passaram pelo método proposto, em egressos de dois anos anteriores e em alunos das fases iniciais. Ao comparar os resultados de cada grupo, evidenciou-se que a PBL, tal qual aplicada, contribuiu de forma significativa na construção de uma visão mais abrangente no estudante acerca da ESW e o impacto de seus produtos na sociedade.

PALAVRAS-CHAVE: Interdisciplinaridade. Educação integral. Engenharia de software.

RESUMEN: La educación superior es determinante en la construcción de una sociedad en sus diferentes dimensiones. La capacidad de resolver problemas requiere competencias interdisciplinarias. El objetivo de esta investigación-acción fue evaluar la efectividad del problem-based learning (PBL) para la enseñanza interdisciplinaria en ingeniería de software (ESW). Fueron realizadas tutorias con alumnos de un curso de Sistemas de Información. Un cuestionario fue aplicado a aquellos que pasaron por el método propuesto, a los egresados de dos años anteriores y a los alumnos de las fases iniciales. Al comparar los resultados de cada grupo, se evidenció que la PBL, tal cual aplicada, contribuyó de forma significativa en la construcción de una visión más amplia en el estudiante acerca de la ESW y el impacto de sus productos en la sociedad.

\section{PALABRAS CLAVE: Interdisciplinariedad. Educación integral. Ingeniería de software.}

\footnotetext{
${ }^{1}$ Instituto Federal de Santa Catarina (IFSC), Caçador - SC - Brasil. Professor EBTT. Doutorando no Programa de Pós-Graduação em Informática na Educação (UFRGS). ORCID: http://orcid.org/0000-0001-7283-3106. Email: paulo.cordova@ifsc.edu.br

${ }^{2}$ Universidade Alto Vale do Rio do Peixe (UNIARP), Caçador - SC - Brasil. Docente e Pesquisador do Programa de Pós-Graduação em Desenvolvimento e Sociedade e do Mestrado Profissional em Educação (EST). ORCID: http://orcid.org/0000-0001-7353-6648.E-mail: baadejoel@gmail.com

3 Universidade Alto Vale do Rio do Peixe (UNIARP), Caçador - SC - Brasil. Docente. Doutorado em Engenharia e Gestão do Conhecimento (UFSC). ORCID: http://orcid.org/0000-0003-3916-972X. E-mail: adelciomachado@gmail.com
} 
ABSTRACT: Higher education is determinant in the construction of a society in its different dimensions. The ability to solve problems requires interdisciplinary skills. The goal of this action research was to evaluate the effectiveness of problem-based learning (PBL) for interdisciplinary teaching in software engineering (ESW). Tutorials were conducted with students of an Information Systems course. A questionnaire was applied to those who experienced the proposed method, also applied to former students who had graduated two years ago and to the students of the initial phases. When comparing the results of each group, it was evidenced that the PBL, as applied, contributed significantly to the construction of a more comprehensive view of the student about ESW and the impact of its products on society.

KEYWORDS: Interdisciplinarity. Full education. Software Engineering.

\section{Introdução}

A Constituição da República Federativa do Brasil, em seu artigo 205, determina que a educação deve visar "ao pleno desenvolvimento da pessoa, seu preparo para o exercício da cidadania e sua qualificação para o trabalho" (BRASIL, 1988, p. 123). No que concerne, mais especificamente, à educação superior, a LDB (1996) em seu artigo 43, estabelece entre as finalidades deste nível de educação: o estímulo à "criação cultural e ao desenvolvimento do espírito científico e do pensamento reflexivo"; a formação de diplomados "aptos para a inserção em setores profissionais e para a participação no desenvolvimento da sociedade brasileira"; o estímulo ao "conhecimento dos problemas do mundo presente, em particular os nacionais e regionais" e; "prestar serviços especializados à comunidade e estabelecer com esta uma relação de reciprocidade" (BRASIL, 1996, p. 32-33).

Estas concepções pressupõem que a educação deve ser integral, viabilizando, conforme Rios (2009) não apenas a formação na dimensão técnica, mas também nas dimensões, estética, política e ética. Nesse contexto, com relação aos cursos de graduação na área da computação, as suas Diretrizes Curriculares Nacionais incluem entre suas recomendações: a "implementação da interdisciplinaridade", a "integração entre teoria e prática" e a "investigação como instrumento para as atividades de ensino" (BRASIL, 2016, p. 2). Isto porque uma formação superespecializada, que desconsidere as múltiplas interações disciplinares presentes em problemas reais, deixa de atender, não só ao princípio constitucional de educação, como às necessidades contemporâneas acerca do que se espera de um profissional.

Por esta razão, acredita-se que um processo formativo interdisciplinar pode ser um caminho efetivo para a condução de uma educação integral. A interdisciplinaridade, por sua 
vez, apesar de não ser ainda possível, conforme afirma Fazenda (2012), apontar uma definição universal e consensual capaz de conceitua-la claramente, neste trabalho adota-se a definição que a descreve como o resultado da "organização da ciência para um fim" (JANTSCH, 1970, p. 15), levando à concepção de uma axiomática comum a um conjunto de disciplinas, com o objetivo de atender a uma dada finalidade. Esta definição está alinhada também com o que diz Carneiro Leão (1991), que afirma que a finalidade é o propósito maior dos avanços científicos, e que da interação interdisciplinar é que surgem as tecnologias para atender a estes fins específicos.

No contexto educacional, Severo (2018) afirma que o trabalho interdisciplinar pode contribuir significativamente para a superação das fronteiras impostas pelo currículo vigente na maioria das instituições de ensino, onde o conteúdo é segmentado e isolado em unidades curriculares. Nesse sentido, segundo Córdova e Baade (2017), uma das técnicas de ensinoaprendizagem capazes de promover interações interdisciplinares com finalidades bem direcionadas, atendendo, portanto, aos requisitos de um ensino interdisciplinar, é a ProblemBased Learning (PBL). Isto porque, segundo Schmidt (1983), entre os princípios da PBL estão: a ativação de conhecimentos prévios, a especificidade de codificação e a elaboração do conhecimento pelo aluno. Estes princípios auxiliam no desenvolvimento de habilidades de resolução de problemas a partir da interação com situações reais, por meio de saberes interdisciplinares e colocando o discente como protagonista do processo.

Entretanto, apesar das recomendações nas diretrizes nacionais curriculares e das possibilidades possíveis com a PBL, poucas ações efetivas são observadas no âmbito dos cursos de graduação na área da computação para a promoção de uma educação que supere os interesses prioritariamente técnicos ou mercadológicos.

O objetivo deste trabalho foi avaliar se as possibilidades identificadas para a PBL, como técnica de ensino-aprendizagem, para a condução de um processo formativo interdisciplinar se concretizam e são capazes de promover uma educação mais próxima da integral. Para isso, usando a técnica das sete etapas de Schmidt (1983), realizou-se uma intervenção junto a acadêmicos de uma universidade do meio oeste de Santa Catarina, Brasil. Esta intervenção consistiu na condução de aulas com aplicação da PBL. Posteriormente realizou-se a avaliação da eficácia do método aplicado, por meio da aplicação de um questionário em três grupos distintos.

Os resultados trazem uma importante contribuição para educadores da área computação, mais especificamente, da engenharia de software. Acreditamos que a busca por melhorias no processo formativo deve ser constante na profissão de educador. 


\section{Métodos}

Este trabalho é o resultado de um ano de pesquisa-ação realizada em uma universidade do meio oeste de Santa Catarina, Brasil. Trata-se de uma intervenção no projeto integrador e estágio supervisionado obrigatório de uma mesma turma do curso de graduação em Sistemas de Informação, no segundo semestre de 2017 e primeiro semestre de 2018, respectivamente. Participaram da pesquisa-ação, alunos regularmente matriculados nas unidades curriculares citadas.

A intervenção se deu por meio da aplicação de uma abordagem de ensinoaprendizagem usando a problem-based learning (PBL), mais especificamente, o modelo das sete etapas proposto por Schmidt (1983). A figura 1 apresenta uma síntese dos trabalhos desenvolvidos no decorrer da pesquisa-ação.

Figura 1 - Síntese do trabalho desenvolvido durante a pesquisa

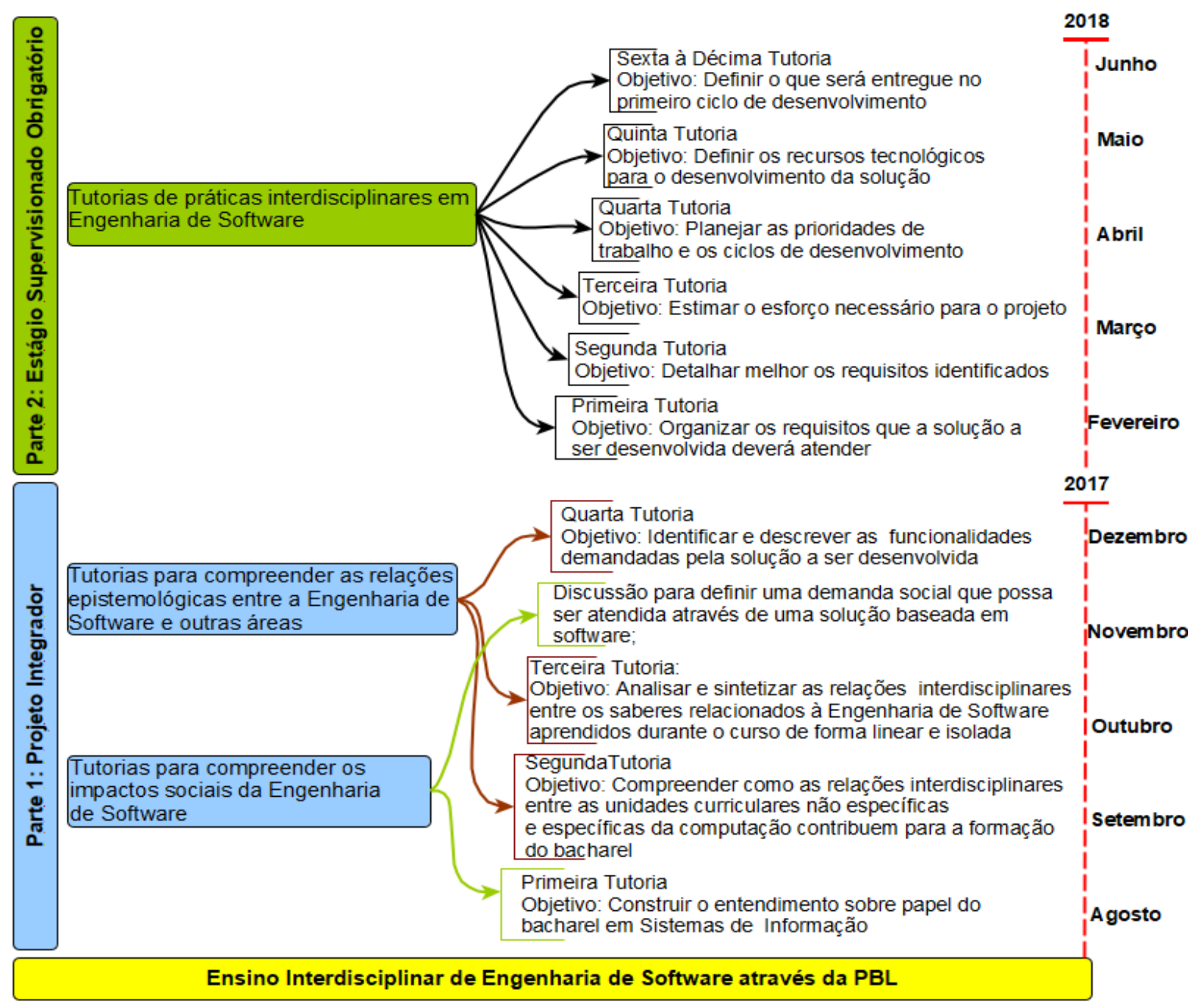

Fonte: Cordova (2018) 
Conforme a proposta demonstrada na figura 1, as atividades de ensino-aprendizagem realizadas tiveram três objetivos centrais: promover a compreensão sobre os impactos sociais da Engenharia de Software, atendendo aos requisitos para formação humanística e social prevista nas Diretrizes Curriculares Nacionais (2011) para os cursos da área da computação; promover a compreensão sobre as relações epistemológicas interdisciplinares entre a Engenharia de Software e outras áreas de conhecimento e; efetuar vivências práticas sobre os saberes construídos pelos discentes. Cada um destes objetivos foi atendido por uma ou mais tutorias.

Para medir a efetividade da intervenção realizada, propôs-se a criação de um instrumento de avaliação da compreensão interdisciplinar acerca da engenharia de software. Este instrumento, que foi materializado na forma de um questionário estruturado, teve como objetivo avaliar se os discentes desenvolveram uma compreensão que ultrapassasse as fronteiras puramente técnicas e chegasse ao entendimento sobre os impactos sociais, éticos, políticos e estéticos que suas produções nesta área podem gerar no contexto em que se encontram.

O questionário foi composto de duas dimensões: o entendimento sobre os impactos sociais da engenharia de software e; o entendimento sobre as relações epistemológicas interdisciplinares entre esta área e demais ciências. Por ter como fím avaliar as competências interdisciplinares e o pensamento sistêmico dos discentes, optou-se pela formulação de questões que, seguindo os preceitos de Edgar Morin (2002), priorizaram: a reconstrução do complexo em detrimento da simplificação pelo método redutivo e da linearidade; a contextualização dos saberes em detrimento da abstração resultante do processo de atomização e; retomar a multidimensionalidade dos objetos do mundo real como princípio.

A tabela 1 mostra as relações entre o questionário e o referencial teórico que orientou este trabalho, bem como as dimensões e as categorias nas quais está dividido. 
Tabela 1 - Relação entre questionário e referencial teórico

\begin{tabular}{|c|c|c|}
\hline Dimensões & Categorias & Referencial Teórico \\
\hline \multirow[t]{3}{*}{$\begin{array}{l}\text { Entendimento } \\
\text { sobre os impactos } \\
\text { sociais da } \\
\text { Engenharia de } \\
\text { Software }\end{array}$} & $\begin{array}{l}\text { Consciência quanto à importância da } \\
\text { formação científica; }\end{array}$ & $\begin{array}{l}\text { (BRASIL, Conselho Nacional de Educação. } \\
\text { Diretrizes Curriculares Nacionais para os cursos } \\
\text { de graduação em computação, 2011, p. 5); } \\
\text { (BRASIL, Conselho Nacional de Educação. } \\
\text { Diretrizes Curriculares Nacionais para os cursos } \\
\text { de graduação em computação, 2011, p. 8); } \\
\text { (BRASIL, Conselho Nacional de Educação. } \\
\text { Diretrizes Curriculares Nacionais para os cursos } \\
\text { de graduação em computação, 2016, p. 3); } \\
\text { (SWEBOK, 2004, p. 224-256); }\end{array}$ \\
\hline & $\begin{array}{l}\text { Consciência } \begin{array}{l}\text { sobre } \\
\text { ambientais e }\end{array} \text { impactos } \\
\text { tecnológicas em das produções } \\
\text { software; }\end{array}$ & $\begin{array}{l}\text { (BRASIL, Conselho Nacional de Educação. } \\
\text { Diretrizes Curriculares Nacionais para os cursos } \\
\text { de graduação em computação, 2011, p. 5); } \\
\text { (RIOS, 2009, p. 16); } \\
\text { (SWEBOK, 2004, p. 224-256); }\end{array}$ \\
\hline & $\begin{array}{l}\text { Espírito empreendedor e ética ao propor } \\
\text { novas soluções; }\end{array}$ & $\begin{array}{l}\text { (MORIN, 2002, p. 40-41); } \\
\text { (RIOS, 2009, p. 16); } \\
\text { (BRASIL, Conselho Nacional de Educação. } \\
\text { Diretrizes Curriculares Nacionais para os cursos } \\
\text { de graduação em computação, 2011, p. 5); } \\
\text { (BRASIL, Conselho Nacional de Educação. } \\
\text { Diretrizes Curriculares Nacionais para os cursos } \\
\text { de graduação em computação, 2011, p. 2); } \\
\text { (BRASIL, Conselho Nacional de Educação. } \\
\text { Diretrizes Curriculares Nacionais para os cursos } \\
\text { de graduação em computação, 2016, p. 3); } \\
\text { (SWEBOK, 2004, p. 224-256); }\end{array}$ \\
\hline \multirow{4}{*}{$\begin{array}{l}\text { Relações } \\
\text { epistemológicas } \\
\text { interdisciplinares } \\
\text { entre } \\
\text { Engenharia de } \\
\text { Software e demais } \\
\text { áreas } \\
\text { conhecimento }\end{array}$} & $\begin{array}{l}\text { Relações da Engenharia de Software } \\
\text { com a Matemática; }\end{array}$ & $\begin{array}{l}\text { (JANTSCH, 1970, p. 14-20); } \\
\text { (CARNEIRO LEÃO, 1991, p. 7-8); } \\
\text { (SWEBOK, 2004, p. 257-278); }\end{array}$ \\
\hline & $\begin{array}{l}\text { Relações da Engenharia de Software } \\
\text { com as Ciências Sociais Aplicadas; }\end{array}$ & $\begin{array}{l}\text { (JANTSCH, 1970, p. 14-20); } \\
\text { (CARNEIRO LEÃO, 1991, p. 7-8); } \\
\text { (SWEBOK, 2004, p. 133-147); } \\
\text { (SWEBOK, 2004, p. 174-190); } \\
\text { (SWEBOK, 2004, p. 206-223); }\end{array}$ \\
\hline & $\begin{array}{l}\text { Relações da Engenharia de Software e as } \\
\text { Ciências Humanas; }\end{array}$ & $\begin{array}{l}\text { (JANTSCH, 1970, p. 14-20); } \\
\text { (CARNEIRO LEÃO, 1991, p. 7-8); } \\
\text { (KASHFI; NILSSON; FELDT, 2016, p. 3); } \\
\text { (CARDOZO E SILVA, 2014, p. 26); } \\
\text { (SWEBOK, 2004, p. 32-49); } \\
\text { (SWEBOK, 2004, p. 174-190); }\end{array}$ \\
\hline & $\begin{array}{l}\text { Relações interdisciplinares entre os } \\
\text { processos da engenharia de software; }\end{array}$ & $\begin{array}{l}\text { (JANTSCH, 1970, p. 14-20); } \\
\text { (CARNEIRO LEÃO, 1991, p. 7-8); } \\
\text { (SWEBOK, 2004, p. 148-161); } \\
\text { (SWEBOK, 2004, p. 82-103); }\end{array}$ \\
\hline
\end{tabular}

Fonte: Cordova (2018) 
Quanto à forma de avaliação do questionário, por ser composto de questões de múltipla escolha com escala nominal, cada questão foi formulada para permitir apenas uma resposta correta. Além disso, conforme já citado, o questionário foi dividido em duas dimensões, cada uma com 6 (seis) questões, correspondendo a $50 \%$ da pontuação total a ser atingida.

Nesta pesquisa, foram considerados quatro níveis de compreensão, materializados em quatro conceitos, sendo eles: excelente, bom, satisfatório e insatisfatório. A figura 2 apresenta estes conceitos e suas relações com a pontuação atingida no questionário.

Figura 2 - Escala de pontuação vs Conceito

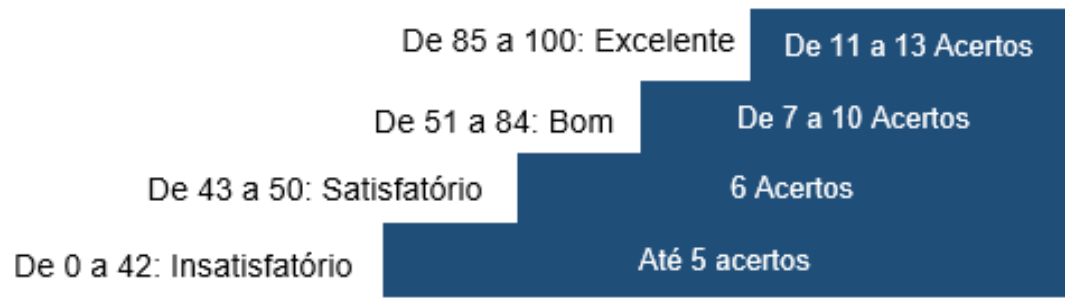

Fonte: Cordova (2018)

De modo a obter um referencial comparativo e identificar outras variáveis que pudessem influenciar na construção das competências interdisciplinares esperadas dos discentes, foram analisados 3 grupos distintos a partir da aplicação do questionário, sendo: alunos que passaram pela PBL; egressos dos anos de 2016 e 2017, que não tiveram qualquer contato com a PBL; alunos das fases iniciais: discentes regularmente matriculados na segunda, quarta e sexta fase do curso de Sistemas de Informação do ano de 2018.

Ao comparar os resultados dos questionários aplicados nestes três grupos, pretendeuse evidenciar se o processo de ensino-aprendizagem aplicado por meio da PBL teve efeito sobre a construção das competências interdisciplinares dos acadêmicos do primeiro grupo. Esta pesquisa passou pela análise e foi aprovada pelo Comitê de Ética em Pesquisa (CEP) da Universidade Alto Vale do Rio do Peixe. O número do parecer de aprovação é 2.820.264.

\section{Discussão e resultados}

Após a aplicação do questionário, foram obtidas 62 respostas de uma população composta por 82 sujeitos. Na tabela 2 é possível observar com mais detalhes este cenário. 
Tabela 2 - Quantidade de respostas por grupo analisado

\begin{tabular}{lccc}
\hline Grupo & $\begin{array}{l}\text { Quantidade de Respostas } \\
\text { Esperadas }\end{array}$ & $\begin{array}{l}\text { Quantidade de Respostas } \\
\text { Obtidas }\end{array}$ & Percentual Obtido \\
\hline $\begin{array}{l}\text { Alunos que passaram } \\
\text { pela PBL }\end{array}$ & 13 & 13 & $100 \%$ \\
$\begin{array}{l}\text { Egressos dos anos de } \\
\text { 2017 e 2018 }\end{array}$ & 27 & 20 & $74 \%$ \\
Alunos das fases iniciais & 42 & & $69 \%$ \\
\hline
\end{tabular}

Fonte: Dados da pesquisa (2018)

Por meio do sistema de gestão acadêmica da instituição onde a presente pesquisa foi realizada, foi possível fazer o levantamento da quantidade de resposta esperadas para cada grupo.

Com relação às dimensões propostas no questionário, as pontuações atingidas por cada um dos grupos são apresentadas na figura 3.

Figura 3 - Pontuação dos grupos estudados por dimensão

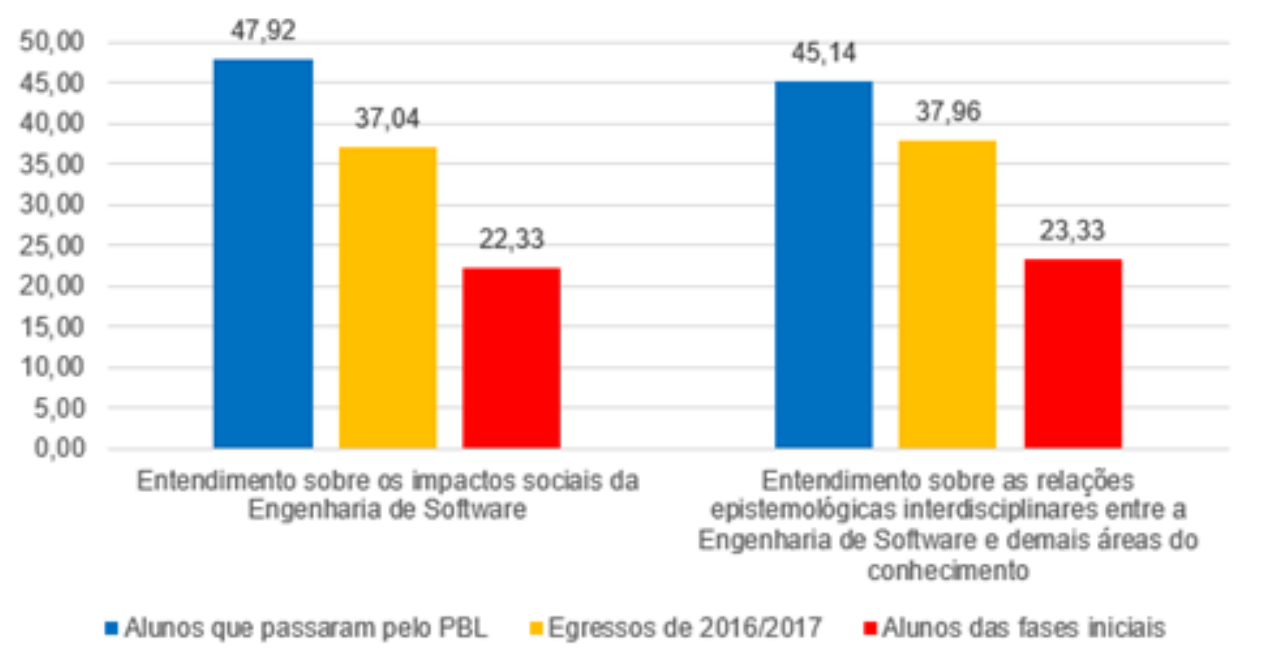

Fonte: Dados da pesquisa (2018)

Como é possível observar, em ambas as dimensões avaliadas, os alunos que passaram pela PBL alcançaram melhor desempenho. Isso fica mais evidente ao considerar a pontuação geral somando as duas dimensões. Nesse caso, tem-se o seguinte cenário: alunos que passaram pela PBL com 93,05 pontos; egressos de 2016/2017 com 75,00 pontos e; alunos das fases iniciais com 45,67 pontos.

Dados os resultados apresentados, a tabela 3 mostra os grupos estudados e os conceitos que atingiram, respectivamente. 
Tabela 3 - Conceito obtido por cada grupo

\begin{tabular}{lcc}
\hline \multicolumn{1}{c}{ Grupo } & Pontuação & Conceito \\
\hline Alunos que passaram pela PBL & 93,05 & Excelente \\
Egressos dos anos de 2017 e 2018 & 75,00 & Bom \\
Alunos das fases iniciais & 45,67 & Satisfatório \\
\hline
\end{tabular}

Fonte: Dados da pesquisa (2018)

É importante destacar que a diferença nas pontuações e, consequentemente, nos conceitos atingidos é bastante significativa. Isso evidencia que, considerando os grupos estudados, a PBL aliada a um planejamento adequado e conduzida de acordo com as diretrizes propostas neste trabalho, teve um efeito bastante evidente na construção das competências pretendidas.

Entretanto, há um fator que deve ser levado em conta ao analisar os resultados obtidos: o efeito da experiência profissional. Isto porque a experiência profissional possibilita, em alguns casos, a interação direta ou indireta com profissionais de outras áreas do conhecimento. Isto pode favorecer a construção de relações e saberes que ajudam a promover uma compreensão mais abrangente, em maior ou menor grau, sobre a própria área de atuação.

Sendo assim, foram considerados como dotados de experiência profissional, os discentes que informaram, ao responder o questionário, que estavam atuando em alguma das áreas da engenharia de software. Nesse contexto, entende-se como área da engenharia de software aquelas que impliquem em esforços necessários para "o desenvolvimento, operação e manutenção de software” (IEEE, 1990, p. 67). Além disso, considerou-se também as áreas previstas no Software Engineering Body of Knoledge (SWEBOK) como referência.

A influência da experiência profissional nos resultados do grupo que passou pela PBL pode ser observada na figura 4 . Neste grupo $46 \%$ dos entrevistados afirmaram estar atuando em alguma das áreas da engenharia de software. 
Figura 4 - Influência da experiência profissional nos resultados dos alunos que passaram pela PBL

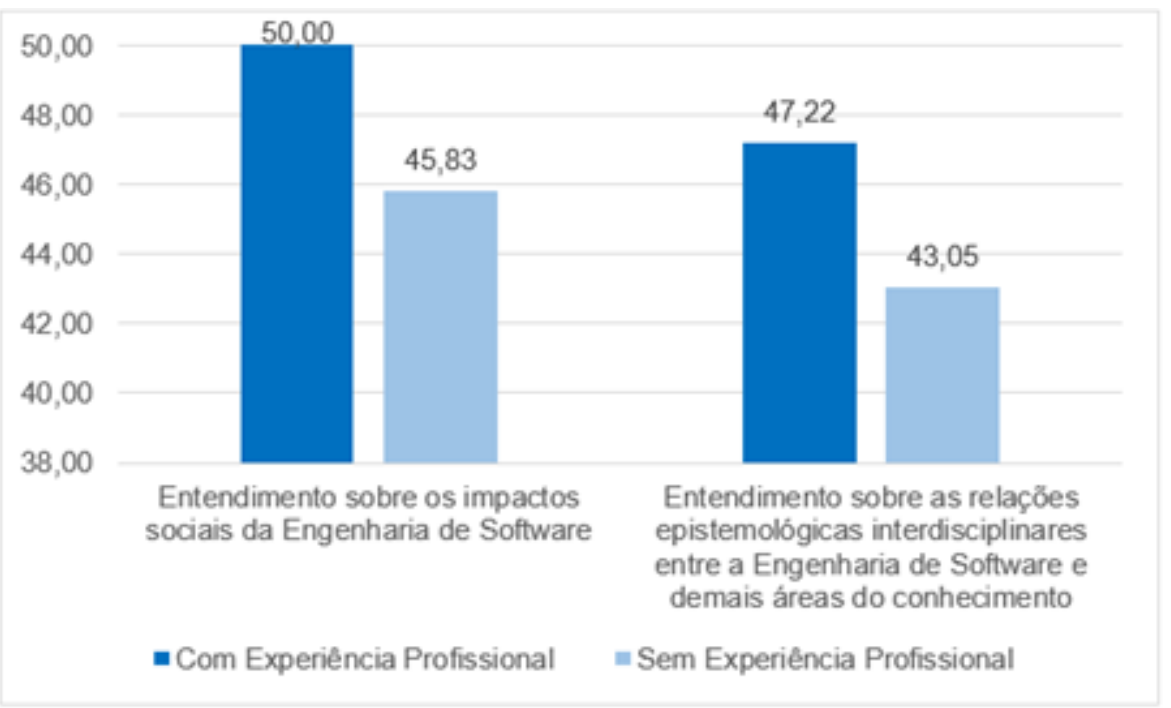

Fonte: Dados da pesquisa (2018)

Observando os resultados, pode-se evidenciar que, embora haja uma clara diferença entre a pontuação atingida por aqueles que atuavam em alguma das áreas da engenharia de software, em relação àqueles que não atuavam, a pontuação de cada subgrupo não se afasta mais do que 5 pontos da média do grupo principal em ambas as dimensões. Além disso, considerando o conceito estabelecido para classificar os resultados obtidos a partir do questionário, ambos mantiveram o conceito excelente.

Da mesma forma, pode-se evidenciar que, neste grupo, os alunos que afirmaram ter experiência profissional atingiram um desempenho melhor em ambas as dimensões analisadas.

O grupo dos egressos de 2016 e 2017, por sua vez, obteve resultados que se diferem um pouco do grupo que passou pela PBL. O percentual da amostra que afirmou contar com experiência profissional no grupo dos egressos é de 50\%, não diferindo significativamente do primeiro neste quesito.

Entretanto, esperava-se que a experiência profissional ajudasse a melhorar a pontuação dos grupos em ambas as dimensões. Apesar disso, os egressos de 2016/2017 que declararam contar com experiência profissional pontuaram menos na dimensão que avalia o entendimento sobre os impactos sociais da engenharia de software.

A figura 5 mostra como esta experiência influenciou na pontuação do grupo dos egressos. 
Figura 5 - Influência da experiência profissional nos resultados dos egressos de 2016 e 2017

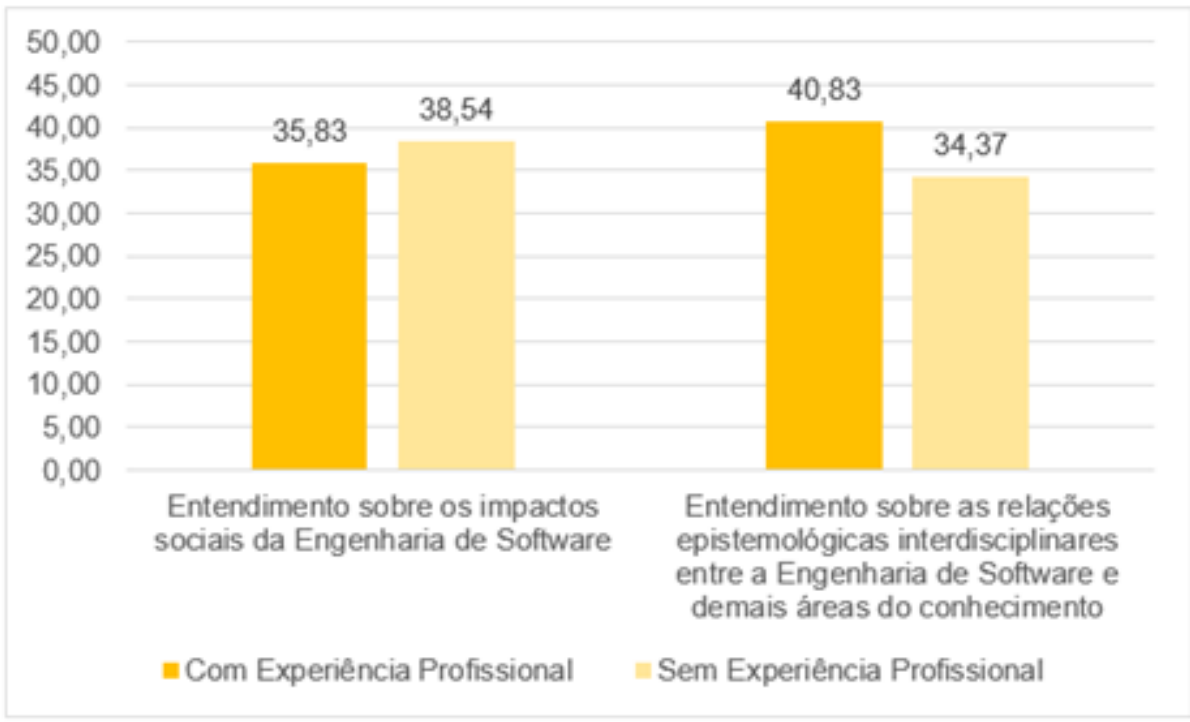

Fonte: Dados da pesquisa (2018)

Pode-se supor que estes resultados se devam às características demasiadamente técnicas exigidas destes profissionais no mercado de trabalho. Mas é necessário que sejam feitas novas pesquisas para confirmar esta hipótese.

Com relação aos conceitos obtidos, da mesma forma que no grupo dos que passaram pela $\mathrm{PBL}$, tanto aqueles que estavam tendo experiência profissional, quanto aqueles que não estavam, apesar da diferença de pontuação, mantiveram o mesmo conceito do grupo principal.

Por fim, ao observar o grupo dos alunos das fases iniciais, onde $17 \%$ dos entrevistados contavam com experiência profissional, nota-se outra diferença em relação aos demais grupos. Neste, conforme pode ser observado na figura 6, a variação de pontuação entre aqueles que declararam contar com experiência profissional e aqueles que declararam não contar é ainda mais significativa.

Este grupo é formado, em sua maior parte, por alunos que passaram por poucas unidades curriculares e, sendo assim, são dotados de menos práticas e horas aula. Por consequência disso, estes discentes não dispõem das mesmas competências já desenvolvidas pelos outros dois grupos.

Esta característica, mostrou ter colocado em vantagem significativa aqueles que contavam com experiência profissional. Evidenciou-se, por exemplo, uma variação maior em relação à média do grupo principal, tanto no subgrupo dos que não tinham experiência profissional, que teve seu conceito baixado para insatisfatório, quanto no subgrupo dos que a tinham, que teve seu conceito aumentado para bom. 
Figura 6 - Influência da experiência profissional nos resultados dos alunos das fases iniciais

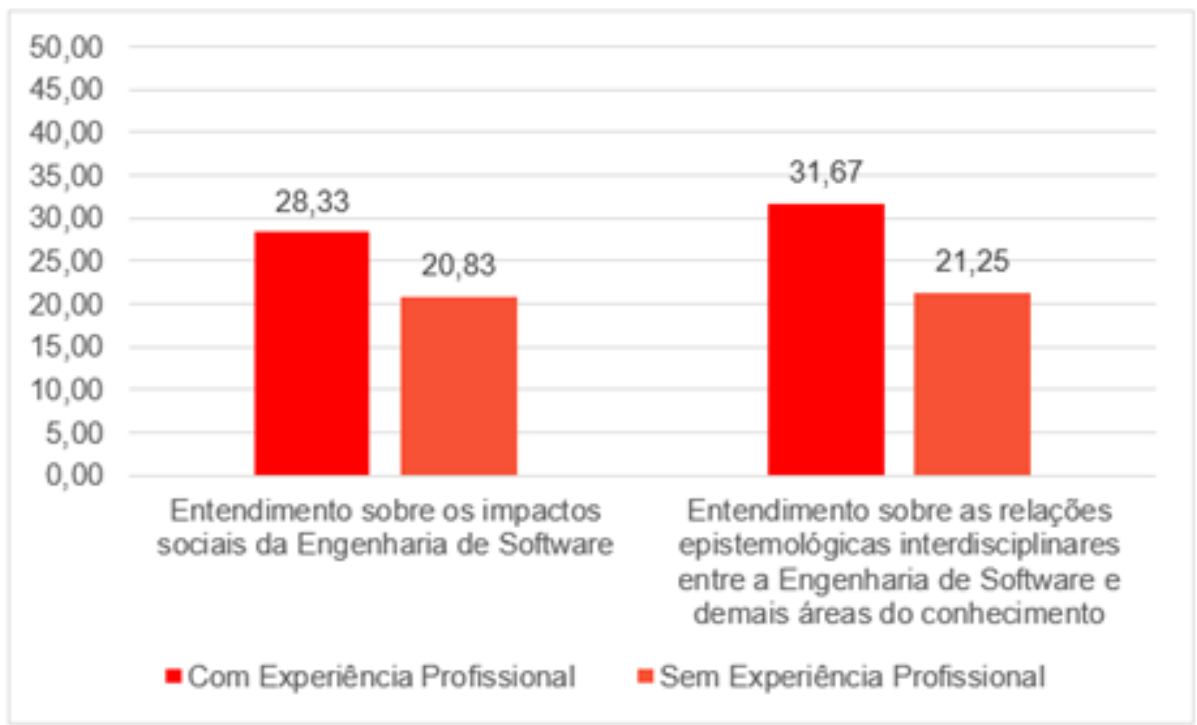

Fonte: Dados da pesquisa (2018)

Pode-se observar na figura 6, que com ou sem experiência profissional, os resultados obtidos pelo grupo composto pelos discentes das fases iniciais se mantém bem abaixo dos demais grupos em ambas as dimensões. É importante destacar, por exemplo, que a melhor pontuação atingida por este grupo não alcança a pior pontuação do grupo dos egressos, que atingiram o segundo melhor conceito. Maior ainda é a diferença se comparada ao grupo que passou pela PBL.

Isso evidencia a importância das competências desenvolvidas ao longo do curso de graduação, sobretudo, considerando o método de ensino-aprendizagem proposto neste trabalho.

Com isso, para melhor demonstrar as diferenças de pontuação entre os grupos analisados, a figura 7 apresenta uma síntese da variação de conceitos e da influência da experiência profissional nos resultados obtidos para cada grupo e subgrupo, considerando a soma das duas dimensões. 
Figura 7 - Síntese da pontuação/conceito e influência da experiência profissional

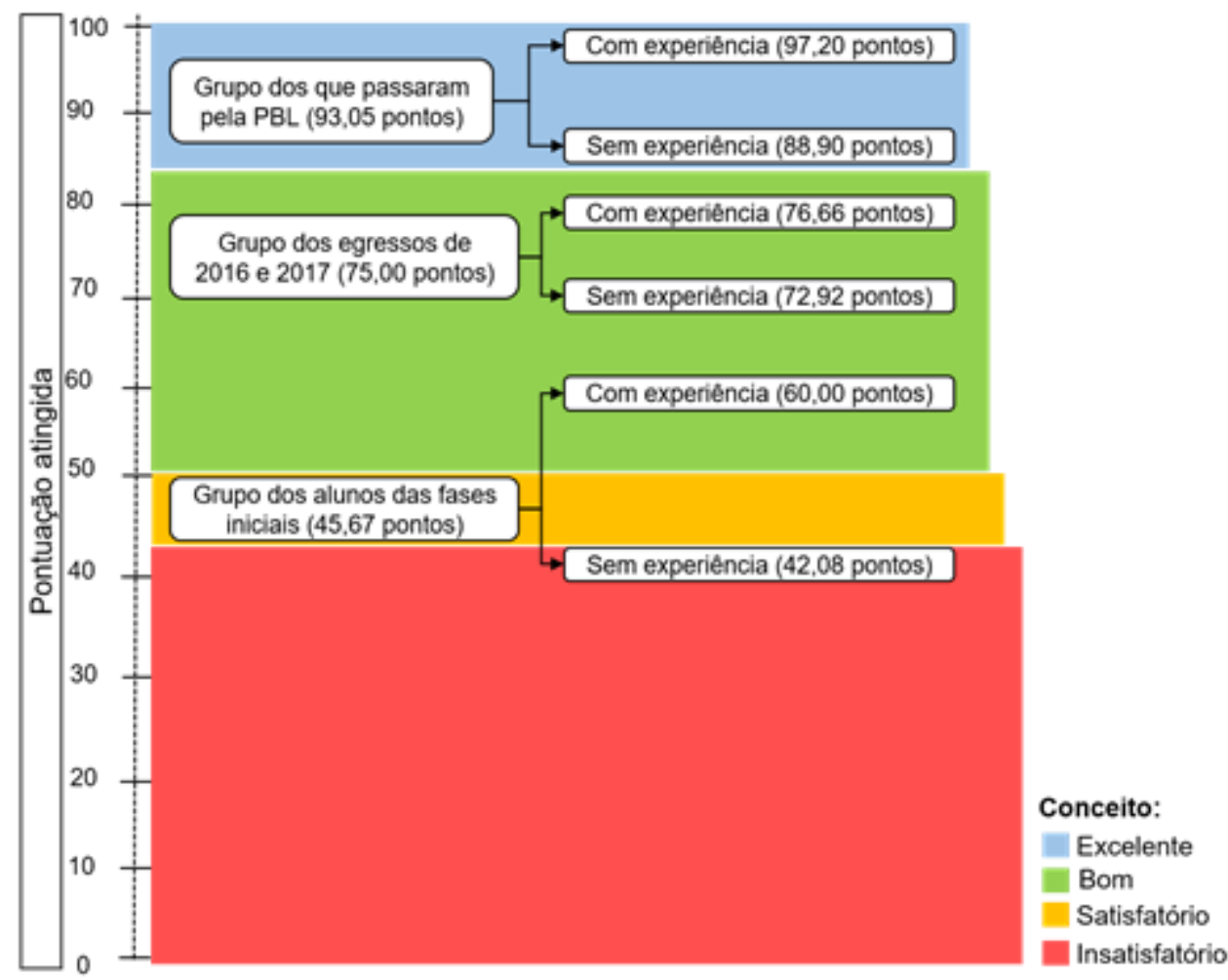

Fonte: Dados da pesquisa (2018)

Como é possível observar, somente no grupo as fases iniciais é que se evidencia uma alteração no conceito dos subgrupos em relação ao grupo principal por influência da experiência profissional. Nos demais grupos esta variável não impactou significativamente.

Dado o exposto, é possível concluir que a experiência profissional contribuiu para o desenvolvimento da compreensão dos entrevistados, nos três grupos e em ambas as dimensões avaliadas. Entretanto, não foi determinante para uma ascensão significativa no conceito geral de cada grupo.

Além disso, pode-se observar que somente os alunos que tiveram a PBL, tal como foi conduzida, em seu processo formativo - mesmo aqueles que não tem experiência profissional - obtiveram conceito excelente. Isto permite inferir que a técnica adotada foi eficaz ao que se propôs: formar cidadãos com maior consciência acerca dos impactos sociais das suas atividades e dotados de uma melhor compreensão acerca das bases interdisciplinares da sua área de atuação.

Estas competências estão alinhadas com as concepções de educação assumidas como verdadeiras na execução deste trabalho e com as definições de Carneiro Leão (1991) e Jantsch (1970) para interdisciplinaridade, uma vez que possibilitam ao estudante, um entendimento sobre a aplicação da Engenharia de Software para a resolução de problemas reais, seja para 
fins mercadológicos, científicos ou sociais, portanto, com uma finalidade ou axiomática comum aos saberes a serem aplicados. Nesse contexto, o emprego prático dos princípios definidos por Schmidt (1983) para PBL, juntamente com um planejamento docente acerca da formulação dos problemas e dos conteúdos a serem trabalhados, possibilitou o sucesso evidenciado por meio dos dados desta pesquisa.

Este cenário possibilita afirmar que, da mesma forma que em outras áreas como a medicina, a contabilidade, a administração, etc., a engenharia de software também pode ser beneficiada pela PBL, quando adequadamente aplicada. Sendo assim, respondendo à questão central desta pesquisa, pode-se afirmar que sim, a PBL contribui para um processo formativo interdisciplinar em Engenharia de Software, visando uma educação integral.

Entretanto, é importante reforçar que, embora a técnica tenha sido um viabilizador importante para o sucesso do processo de ensino-aprendizagem, o planejamento e o trabalho docente, conforme Dalben (2013), são os fatores determinantes deste sucesso. Igualmente importante é o engajamento dos alunos no processo de busca ativa pelo conhecimento.

\section{Considerações finais}

Os resultados apresentados neste trabalho permitem concluir que a PBL consiste em um meio efetivo, cujos princípios e práticas, somadas a um planejamento, conteúdos e processos adequadamente conduzidos pelo docente, possibilita que sejam atingidos resultados satisfatórios no processo formativo em Engenharia de Software. Por meio desta técnica, foi possível conduzir os discentes por um processo de ensino-aprendizagem interdisciplinar, que culminou no desenvolvimento das competências esperadas.

Entretanto, é importante que os processos desenvolvidos nesta pesquisa sejam replicados em outros contextos - turmas do mesmo curso ou de outras instituições de ensino , não apenas para promover a continuidade do trabalho de melhoria no processo formativo, mas também para resolver questões encontradas durante a execução desta pesquisa, como a que se observa na figura 5, onde evidencia-se que os egressos de 2016 e 2017 com experiência profissional pontuaram menos nas questões relacionadas à dimensão que avalia o entendimento sobre os impactos sociais da Engenharia de Software.

Este resultado pode ser a consequência de uma atuação profissional excessivamente técnica. Por esta razão, também novas pesquisas e reflexões sobre como o mundo do trabalho têm influenciado a formação de capital humano são necessárias para confirmar ou refutar esta hipótese. Além disso, a comparação com diferentes resultados da aplicação da técnica 
proposta neste trabalho se faz importante para validar ou não os resultados atingidos neste trabalho.

\section{REFERÊNCIAS}

BRASIL. Conselho Nacional de Educação. Resolução CNE/CES no 5, de 16 de novembro de 2016. Diretrizes Curriculares Nacionais para os cursos de graduação na área da computação. Diário Oficial [da] República Federativa do Brasil, Brasília, Seção 1, p. 22-24, 17 nov. 2016.

BRASIL. Constituição (1988). Constituição da República Federativa do Brasil. Brasília, DF: Senado Federal: Centro Gráfico, 1988. 292 p.

BRASIL. Ministério de Educação e Cultura. Lei n. 9394/96, de 20 de dezembro de 1996. Estabelece as diretrizes e bases da Educação Nacional. Brasília: MEC, 1996.

CARNEIRO LEÃO, E. Para uma crítica da interdisciplinaridade. Revista Tempo Brasileiro, Ribeirão Preto, n. 111, p. 5-20, 1992.

CORDOVA, P. R; BAADE, J. H. Possibilidades para o ensino interdisciplinar de Engenharia de Software usando a Problem-Based Learning (PBL). In: BAADE, J. H.; BONIN, J. C.; HÜLSE, L. Interdisciplinaridade, cidadania e conhecimento: reflexões sobre sociedade, educação, sustentabilidade e desenvolvimento. Caçador: Uniarp, 2017.

CORDOVA, P.R. Processo formativo interdisciplinar em Engenharia De Software por meio da Problem Based Learning (PBL): uma proposta para a formação integral. 2018. 99 f. Dissertação (Mestrado em Desenvolvimento e Sociedade) - Universidade Alto Vale do Rio do Peixe, Caçador, SC, 2018.

DALBEN, Â. I. L. O ensino por meio da resolução de problemas. In: VEIGA, I. P. A. Novas tramas para as técnicas de ensino e estudo. Campinas: Papirus, 2013.

FAZENDA. I. Interdisciplinaridade: história, teoria e pesquisa. 18. ed. Campinas: Papirus, 2012.

Institute of Electrical and Electronics Engineers - IEEE. Guide to the Software Engineering Body of Knowledge (SWEBOK), v3. 2004.

Institute of Electrical and Electronics Engineers - IEEE. Standard Glossary of Software Engineering Terminology, 1990.

JANTSCH, E. Inter-And Transdisciplinary University: a system approach to education and innovation. Elsevier Publishing Company, Amsterdam, v. 1, n. 1, p. 403-428, mar. 1970.

MORIN, E. Os sete saberes necessários à educação do futuro. 2. ed. São Paulo: Cortez, 2002 . 
RIOS, T. A. Ética na docência universitária: a caminho de uma universidade pedagógica. São Paulo: USP, 2009.

SCHMIDT, H. G. Problem-based Learning: rationale and description. Medical Education, v. 17, p. 11-16, 1983.

SEVERO, C. E. P. Os Efeitos Educativos de Práticas Pedagógicas Interdisciplinares Baseadas em Projetos na Educação Profissional e Tecnológica. Interdisciplinaridade, São Paulo, n. 12, p. 32-47, abr. 2018.

\section{Como referenciar este artigo}

CÓRDOVA, P. R.; BAADE, J. H.; SANTOS, A. M. dos. Problem-Based Learning (PBL) e interdisciplinaridade no ensino-aprendizagem de Engenharia de Software. Revista IberoAmericana de Estudos em Educação, Araraquara, v. 15, n. 4, p. 2078-2093, out./dez. 2020. e-ISSN: 1982-5587. DOI: https://doi.org/10.21723/riaee.v15i4.12786

Submetido em: 24/07/2019

Revisões requeridas em: 05/02/2020

Aprovado em: 06/06/2020

Publicado em: 30/08/2020 